\title{
Ant-mediated seed dispersal in a warmed world
}

Climate change affects communities both directly and indirectly via changes in interspecific interactions. One such interaction that may be altered under climate change is the ant-plant seed dispersal mutualism common in deciduous forests of eastern North America. As climatic warming alters the abundance and activity levels of ants, the potential exists for shifts in rates of ant-mediated seed dispersal. We used an experimental temperature manipulation at two sites in the eastern US (Harvard Forest in Massachusetts and Duke Forest in North Carolina) to examine the potential impacts of climatic warming on overall rates of seed dispersal (using Asarum canadense seeds) as well as species-specific rates of seed dispersal at the Duke Forest site. We also examined the relationship between ant critical thermal maxima $\left(\mathrm{CT}_{\max }\right)$ and the mean seed removal temperature for each ant species. We found that seed removal rates did not change as a result of experimental warming at either study site, nor were there any changes in species-specific rates of seed dispersal. There was, however, a positive relationship between $\mathrm{CT}_{\text {max }}$ and mean seed removal temperature, whereby species with higher $\mathrm{CT}_{\text {max }}$ removed more seeds at hotter temperatures. The temperature at which seeds were removed was influenced by experimental warming as well as diurnal and day-to-day fluctuations in temperature. Taken together, our results suggest that while temperature may play a role in regulating seed removal by ants, ant plant seed-dispersal mutualisms may be more robust to climate change than currently assumed. 


\section{Ant-mediated seed dispersal in a warmed world}

3 Katharine L. Stuble ${ }^{1 \dagger}$

4 Courtney M. Patterson ${ }^{1}$

5 Mariano A. Rodriguez-Cabal ${ }^{2 \S}$

6 Relena R. Ribbons ${ }^{1}$

$7 \quad$ Robert R. Dunn ${ }^{3}$

8 Nathan J. Sanders ${ }^{1 \%}$

9

101 Dept. of Ecology \& Evolutionary Biology, University of Tennessee, Knoxville, TN 1137996 , USA

12 Dept. of Zoology, University of British Columbia, Vancouver, B.C. V6T1Z4, Canada

13 Dept. of Biology, North Carolina State University, Raleigh, NC 27695

$14 †$ Current address / Corresponding author: Oklahoma Biological Survey, $111 \mathrm{E}$

15 Chesapeake St, Norman, OK, 73019 USA

16 §Current address: INIBIOMA, CONICET, Universidad Nacional del Comahue,

17 Bariloche, Río Negro - Argentina, 8400

$18+$ Current address: Center for Macroecology, Evolution and Climate, Natural History

19 Museum of Denmark, University of Copenhagen, DK-2100 Copenhagen,

$20 \quad$ Denmark 


\section{Abstract}

23 Climate change affects communities both directly and indirectly via changes in

24 interspecific interactions. One such interaction that may be altered under climate change

25 is the ant-plant seed dispersal mutualism common in deciduous forests of eastern North

26 America. As climatic warming alters the abundance and activity levels of ants, the

27 potential exists for shifts in rates of ant-mediated seed dispersal. We used an experimental

28 temperature manipulation at two sites in the eastern US (Harvard Forest in Massachusetts

29 and Duke Forest in North Carolina) to examine the potential impacts of climatic warming

30 on overall rates of seed dispersal (using Asarum canadense seeds) as well as species-

31 specific rates of seed dispersal at the Duke Forest site. We also examined the relationship

32 between ant critical thermal maxima $\left(\mathrm{CT}_{\max }\right)$ and the mean seed removal temperature for

33 each ant species. We found that seed removal rates did not change as a result of

34 experimental warming at either study site, nor were there any changes in species-specific

35 rates of seed dispersal. There was, however, a positive relationship between $\mathrm{CT}_{\max }$ and

36 mean seed removal temperature, whereby species with higher $\mathrm{CT}_{\max }$ removed more seeds

37 at hotter temperatures. The temperature at which seeds were removed was influenced by

38 experimental warming as well as diurnal and day-to-day fluctuations in temperature.

39 Taken together, our results suggest that while temperature may play a role in regulating

40 seed removal by ants, ant plant seed-dispersal mutualisms may be more robust to climate

41 change than currently assumed.

43 Keywords: ants, climate change, myrmecochory, seed dispersal, warming 


\section{Introduction}

46 Understanding how organisms will respond to ongoing changes in climate,

47 leading to subsequent changes in key ecological processes, is essential in order to predict

48 the structure and function of ecosystems in the future (Andrew et al. 2013). For example,

49 the alteration of interspecific interactions is one important mechanism by which climate

50 change may ultimately alter the structure and function of ecosystems (Tylianakis et al.

51 2008, van der Putten et al. 2010, Walther 2010, Harley 2011, Urban et al. 2012). The

52 majority of studies on the effects of climate change on interspecific interactions have

53 focused on negative interactions, such as competition (Suttle et al. 2007), predator-prey

54 interactions (Rothley and Dutton 2006, Barton and Schmitz 2009, Harley 2011), and

55 herbivory (Bale et al. 2002). Indeed, climate change can alter the nature and outcomes of

56 interspecific interactions through a variety of mechanisms such as altered abundance and

57 fitness levels of key species (Suttle et al. 2007), shifts in phenology (Both et al. 2009),

58 and species range shifts (Harley 2011). Each of these mechanisms can disrupt

59 interspecific interactions by altering the frequency and intensity of interactions among

60 species.

61 As with most studies in ecology, work on the effects of climate change on positive

62 interactions is lacking, even though mutualisms play fundamental roles in structuring

63 communities and ecosystems (Callaway 1995, Stachowicz 2001). Mutualisms including

64 plant-pollinator interactions and mycorrhizal interactions have been altered by climate

65 change (Parrent et al. 2006, Memmott et al. 2007, Hoover et al. 2012). However, the

66 influence of climate change on other types of positive interactions is not as well studied. 
One such mutualism that may be altered by climate change is myrmecochory, the

68 ant-plant seed dispersal mutualism. This mutualism includes hundreds of ant species and

69 thousands of plant species around the world (Beattie and Hughes 2002, Gove et al. 2007,

70 Rico-Gray and Oliveira 2007, Lengyel et al. 2010) and can play an important role in

71 shaping plant communities (Bond and Slingsby 1984). Myrmecochorous plant species

72 typically bear seeds containing a lipid-rich fleshy appendage known as an elaiosome, to

73 which ants are attracted. In deciduous forests of North America approximately thirty

74 percent of understory herb species might be ant-dispersed (Beattie and Culver 1981), and

75 a proposed keystone seed-dispersing ant species, Aphaenogaster rudis, is responsible for

76 upwards of 90\% of ant-mediated seed dispersal (Zelikova et al. 2008, Ness et al. 2009).

77 Such specialization in interactions can make interaction networks more vulnerable to

78 disruption as a result of low levels of functional redundancy within a system (Aizen et al.

79 2012). Myrmecochorous plant species that rely on a single ant species (or species

80 complex) for seed dispersal may be at increased risk for disruption by ongoing climatic

81 change (Pelini et al. 2011a, Warren et al. 2011, Warren and Bradford 2013) if that ant

82 species is negatively affected by warming. Inversely, systems in which multiple species

83 are responsible for removing seeds may prove to be more resistant to disruptions because

84 of functional redundancy in the system (Peterson et al. 1998). However, despite the

85 importance and ubiquity of myrmecochory in ecosystems around the world and the

86 importance of temperature in regulating ant foraging, experiments examining the

87 consequences of climatic change on this mutualism are rare (but see Pelini et al. 2011a,

88 Warren and Bradford 2013). 
To examine the potential for climate change to alter myrmecochory, we

90 experimentally manipulated temperature at two sites in the eastern United States (Duke

91 Forest in North Carolina and Harvard Forest in Massachusetts) and examined overall

92 rates of seed removal as a function of temperature. At the North Carolina site, we also

93 examined species-specific rates of seed dispersal. We test two predictions:

94 Prediction 1: Rates of seed removal by ants would decrease as a result of experimental

95 warming at the southern site where species, including A. rudis, are closer to their critical

96 thermal maxima ( $\left.\mathrm{CT}_{\max }\right)$ (Deutsch et al. 2008, Diamond et al. 2012a, Diamond et al.

97 2012b, Huey et al. 2012), a pattern previously documented in this study system (Diamond

98 et al. 2012a). Rates of seed removal can be expected to increase at the northern site,

99 where most species, including A. rudis, are well below their $\mathrm{CT}_{\max }$ (Diamond et al.

100 2012a) and perhaps even below their thermal optima.

101 Prediction 2: Species with higher $\mathrm{CT}_{\max }$ would remove seeds more readily under warmer

102 conditions as compared to species with lower $\mathrm{CT}_{\max }$ as these species are more tolerant of

103 higher temperatures and have been found to be more active as temperatures increase

104 (Stuble et al. 2013a).

105

106 Methods

107 Site description

108 This experiment was conducted at Duke Forest (southern site) in North Carolina

109 and Harvard Forest (northern site) in Massachusetts, United States (U.S.), in order to

110 examine the potential impacts of climate change on seed dispersal mutualisms near the

111 southern and northern extents of eastern deciduous forests. The Duke Forest site consists 
112 of a closed-canopy oak-hickory (Quercus spp., Carya spp.) forest with a mean annual

113 temperature of $15.5^{\circ} \mathrm{C}$ and approximately $1140 \mathrm{~mm}$ of precipitation annually. The

114 Harvard Forest site is in a closed-canopy oak-maple (Quercus spp.-Acer spp.) forest with

115 a mean annual temperature of $7.1^{\circ} \mathrm{C}$ and $1066 \mathrm{~mm}$ of precipitation a year. Though not

116 present in the immediate vicinity of this experiment, several myrmecochorous plant

117 species are common in these forests. These species include Asarum canadense, Asarum

118 arifolium, Trillium spp., Violia rotundifolia, and Sanguinaria canadensis, among others.

119 Seeds of these plant species, and myrmecochorous species in general, are typically

120 dispersed in the spring (Thompson 1981).

121 Approximately 30 ant species co-occur at the two sites, with the North Carolina site near

122 the southern range edge and the Massachusetts site near the northern range edge for many

123 of these species (Pelini et al. 2011b). The most abundant ant species at both sites, as is the

124 case throughout eastern deciduous forests (King et al. 2013), is the proposed keystone

125 seed disperser A. rudis (Ness et al. 2009) (or at least a species in the taxonomically

126 vexing $A$. rudis complex). For the purposes of this study we are combining A. rudis, $A$.

127 picea, and A. carolinensis into the A. rudis complex due to the difficultly of identifying

128 these closely related species in the field. Crematogaster lineolata, a behaviorally

129 aggressive species, can be abundant at the southern site in warmer months while Formica

130 subsericea and Camponotus pennsylvanicus (also behaviorally aggressive) are the two

131 next most abundant ant species at the Harvard Forest site (Stuble et al. 2013b).

132 At each site, there are twelve experimental open-top warming chambers (Fig. 1).

133 Each chamber is $5 \mathrm{~m}$ in diameter and $1.2 \mathrm{~m}$ tall with a $2-3 \mathrm{~cm}$ gap at the bottom to allow

134 ants and other organisms to move in and out. The chambers are large relative to the size 
135 of an ant (i.e. about 1000 body lengths across). Nine chambers at each site are warmed

136 from $1.5^{\circ} \mathrm{C}$ to $5.5^{\circ} \mathrm{C}$ in $0.5^{\circ} \mathrm{C}$ steps using air warmed by hydronic radiators, while the

137 three control chambers blow air at ambient temperatures into the plots (see Pelini et al.

138 (2011b) for a detailed description of the chambers). Warming treatments have been

139 maintained continuously since January of 2010 and have been successful at maintaining

140 the targeted temperature increases. For 2011, a significantly positive relationship between

141 the target temperature and actual temperature increase was maintained $\left(\mathrm{p}<0.01, \mathrm{R}^{2}=\right.$

$1420.99)$.

143 The chambers contain about one $A$. rudis colony per square meter while the

144 average foraging distance of an $A$. rudis colony is $\sim 70 \mathrm{~cm}$ (L. Nichols, unpublished data).

145 In addition, during the summer of 2012, we watched 72 A. rudis workers visiting baits

146 and returning to their colonies. Out of those 72 observations, only 1 worker visited a bait

147 in the chamber and returned to a nest outside the chamber (L. Nichols, unpublished data).

148 So, most of the activity we see is from ants in the chambers. Significant shifts in levels of

149 foraging activity at food baits have been documented in the chambers across the

150 temperature treatments for a variety of ant species, with more thermally tolerant species

151 exhibiting higher levels of foraging activity in warmer chambers than species with lower

152 thermal tolerances (Stuble et al. 2013a). Those results suggest that temperature does

153 mediate foraging behavior. Such a result, that environmental context can mediate

154 foraging behavior, is in line with previous work in this system (Pelini et al. 2011) and

155 others (Cerdá et al. 1997, Sanders and Gordon 2000, 2003, Gibb and Parr 2010).

156

157 Seed removal 
To assess the impact of temperature on rates of seed dispersal, we haphazardly

159 positioned one seed cache in each of the 12 chambers at Duke Forest and Harvard Forest.

160 Each cache contained 20 seeds of the myrmecochorous species Asarum canadense placed

161 on a laminated index card. The range of Asarum canadense extends from New

162 Brunswick, Canada to North Carolina in the southern US (Cain and Damman 1997).

163 Seeds of $A$. canadense are similar in mass to many other myrmecochorous plant species

164 (Michaels et al. 1988), including the locally common Sanguinaria canadensis and

165 Asarum arifolium, and are readily removed by A. rudis (Turner and Frederickson 2013).

166 Seeds used in the trials at Duke Forest were collected at North Carolina State University's

167 Schenck Forest in Raleigh, North Carolina on May 11, 2011 and those used in the

168 Harvard Forest trials were collected from Mt. Toby in Massachusetts on June 8, 2011

169 when seeds of this species naturally dehisce at these locations. Seeds were kept frozen

170 until used in a trial (Morales and Heithaus 1998). We covered each seed cache with a

171 mesh cage $(14.25 \mathrm{~cm}$ long $\times 14.25 \mathrm{~cm}$ wide $\times 7.5 \mathrm{~cm}$ tall, mesh size $1 \mathrm{~cm} \times 1.5 \mathrm{~cm})$ to

172 allow ants to access the seeds while preventing access by rodents. Caches were left out

173 for one hour, after which time the number of seeds remaining in the cache was counted

174 and any remaining seeds were removed from the chamber. Though observing seed

175 removal for an hour limits our ability to account for the fate of all seeds, using this

176 standard timeframe allowed us to compare relative rates of seed removal across

177 treatments. A total of ten trials (one seed cache deployed per chamber) were conducted at

178 Duke Forest between May 12 and May 25, 2011, with five trials conducted during the

179 day (between 0900 and 1900) and five during the night (between 2100 and 0500).

180 Another five trials were conducted at Harvard Forest between June 16 and June 30, 2011: 
181 three during the day and two at night. These dates corresponded with the time periods

182 during which the seeds were naturally released at each site, as opposed to conducting this

183 experiment in the hottest part of the year when the impacts of warming might be expected

184 to be greater, but when any results might be less ecologically relevant.

185 We calculated the average seed dispersal rate (number of seeds removed in an

186 hour) for each chamber at each site. We used ANCOVA to examine differences in seed

187 dispersal rates as a function of temperature treatment (which we refer to as $\Delta^{\circ} \mathrm{C}$, included

188 as a continuous variable) and site. The number of seeds removed per hour was square

189 root transformed to meet assumptions of normality. All statistics were performed in SAS,

190 version 9.2.

191 To determine the ant species responsible for removing the seeds, we continuously

192 observed caches of 10 A. canadense seeds within the chambers at Duke Forest for one

193 hour, or until all seeds were removed. Four seed removal observations were conducted in

194 each chamber: two during the day and two during the night. Nighttime observations were

195 conducted using red lights, which is typical in studies of ant behavior at night (Hodgson

196 1955, Narendra et al. 2010). We recorded the identity of the ant species removing the

197 seeds. When possible, we also followed the seed back to the nest (or under leaf litter in

198 some cases) and noted the distance it had been moved. At the beginning of each

199 observation, we took four ground surface temperature measurements using a handheld

200 infrared thermometer (Raytek ${ }^{\circledR}$ Raynger ST, $+/-1{ }^{\circ} \mathrm{C}$ ), one at each corner of the seed

201 cache, which were averaged together. These temperature readings provided us with

202 estimates of ground-surface temperature conditions in the immediate vicinity of the

203 seeds. Ground-surface temperature has been shown to be an important driver of foraging 
204 activity in ants (Whitford and Ettershank 1975, Crist and MacMahon 1991). We

205 calculated the percentage of seeds removed by each species overall, as well as separately

206 for day and night. We also calculated the mean number of seeds removed by each species

207 in each chamber across all trials.

208 We used linear regressions to examine the relationship between seed dispersal rate

209 and temperature treatment for each ant species. (We examined several polynomial

210 regressions, but found none of them to be a better fit than simple linear regressions.

211 Generalized linear models also yielded qualitatively similar results.) Mean numbers of

212 seeds removed (per species and chamber) were log transformed to meet assumptions of

213 normality for $A$. rudis and C. lineolata.

214 Finally, we calculated the average ground surface temperature (based on

215 temperatures collected with the infrared thermometer) at which each species removed

216 seeds across all treatments and times. We then examined the relationship between the

217 average temperature at which a species removed seeds and the $\mathrm{CT}_{\max }$ of that species (as

218 calculated by Diamond et al., 2012 at or near the study site at the same time of year as

219 this study was conducted) across all species observed removing seeds in the system.

220 Aphaneogaster lamellidens was excluded from this analysis as it was only observed

221 removing seeds from two seed caches and was an outlier (as indicated by a plot of

222 residuals by predicted values).

223

224 Results and Discussion

225 Seed removal rate did not depend on temperature treatment $\left({ }^{\circ} \mathrm{C}\right.$ above ambient) 226 and did not vary between sites $\left(F_{2,21}=0.93, p=0.41\right.$; Fig. 2$)$. This result is despite the 
227 fact that most of the foragers observed in this study were from colonies within the

228 experimental chambers. At the southern site, where seed dispersal observations were

229 conducted, the mean seed removal distance was $51 \mathrm{~cm}$, and only $2 \%$ of observed seeds

230 were removed more than $2 \mathrm{~m}$. The lack of response to experimental warming contrasts

231 with the prediction that, based on the thermal limits of $A$. rudis and its disproportionate

232 role in seed dispersal, seed dispersal rate should decline with increasing temperatures.

233 Regardless of temperature treatment or site, ants removed $\sim 23 \%$ of seeds per hour (an

234 average of 4.6 seeds out of 20). At the southern site, we observed seven ant species

235 removing seeds across a range of ground surface temperatures from $17^{\circ} \mathrm{C}$ to $30^{\circ} \mathrm{C}$ (Table

236 1). Aphaenogaster rudis was the most common seed disperser, removing approximately

$23745.5 \%$ of seeds (Table 2). However, there was no relationship between the rate of seed

238 dispersal by $A$. rudis and temperature treatment (Table 1). With the exception of $C$.

239 lineolata, which showed a marginally significant increase of approximately 0.1 seeds

240 removed per degree of warming, seed removal did not vary systematically with

241 temperature treatment for any ant species (Table 1). This finding is despite previously

242 observed shifts in foraging under experimentally warmed conditions (Pelini et al. 2011a,

243 Stuble et al. 2013a). Pelini et al. (2011a) found an approximately 50\% decrease in several

244 types of foraging, including seed removal, as a result of $1^{\circ} \mathrm{C}$ of warming at the southern

245 site, though no change was observed at the northern site. Using the same warming

246 chambers as in this study, Stuble et al. (2013a) found species-specific shifts in foraging

247 activity as a result of experimental warming consistent with the thermal tolerances of the

248 foraging species. Further, ant community composition shifts in response to experimental

249 warming, demonstrating the importance of temperature in regulating the ant community 
250 (Diamond et al. 2012a). Despite this, experimental warming apparently does not affect

251 the aspects of the seed-dispersal mutualisms we studied in this system. This begs the

252 question - why isn't this seed-dispersal mutualism disrupted by experimental warming?

253 One possible answer is that foraging behavior by Aphaenogaster rudis may be

254 more tolerant of experimental warming than previously thought. A. rudis is a keystone

255 mutualist in this and other systems, responsible for the majority of ant-mediated seed

256 dispersal (Zelikova et al. 2008, Ness et al. 2009, Canner et al. 2012). The abundance and

257 activity of $A$. rudis declines with elevation (i.e., lower temperatures) at biogeographic

258 scales (Zelikova et al. 2008). Additionally, the relatively low thermal tolerance of this

259 species accurately predicts its activity relative to other species (Stuble et al. 2013a).

260 However, when exposed to experimental warming, the abundance (Pelini et al. 2011a)

261 and foraging activity (Stuble et al. 2013a) of A. rudis apparently do not decline at either

262 study site. Importantly, the average foraging distance of Aphaenogaster spp. was $\sim 70 \mathrm{~cm}$

263 at the study site (L. Nichols, unpublished data). Further, based on the proportion of these

264 ants observed foraging into the chambers from outside in observations, we'd predict that

265 only about one of the eighty seeds observed being removed by A. rudis was likely to have

266 been removed by a worker originating outside of the chambers. Thus, it is not likely the

267 case that ants are coming to baits from nests that are outside the chambers. However,

268 even in cases in which individual workers do forage at the experimental baits from

269 colonies outside of the chambers, these individuals are still exposed to the experimental

270 temperature conditions while discovering, foraging at, and recruiting to the seed caches.

271 These results suggest that temperature does not substantially alter this foraging behavior.

272 The apparent tolerance of the foraging activity of this important seed dispersing species 
273 to warming may play a major role in promoting the stability of ant-plant seed dispersal in

274 light of global change.

275 It is important to note that six ant species other than A. rudis were observed

276 removing seeds in this study, and they removed $>50 \%$ of the seeds. This runs counter to

277 several studies suggesting seed dispersal mutualisms may be highly specialized (Gove et

278 al. 2007, Ness et al. 2009). Both the foraging activity and abundances of several of these

279 species, including C. lineolata and Formica pallidefulva, shift with warming (Pelini et al.

280 2011a, Diamond et al. 2012a, Stuble et al. 2013a), resulting in an altered community of

281 foragers (Diamond et al. 2012a). By having multiple ant species interacting with

282 myrmecochorous plants, this ant-plant seed dispersal mutualism may be relatively

283 resistant to the effects of warming as some ant species increase in activity and abundance

284 while others decline in abundance with temperature. Previous work on ant foraging and

285 community composition as a result of the experimental warming at these sites suggests

286 that species vary in their responses to warming, which might moderate the overall effects

287 of climatic warming on entire assemblages (Stuble et al. 2013a).

288 In addition to the apparent (and of course relative) resistance of the foraging of $A$.

289 rudis to warming, along with the diversity of ants engaging in this mutualism, another

290 factor possibly strengthening the resistance of myrmecochory to warming may be the

291 timing of ant-mediated seed dispersal within deciduous forests of the eastern U.S.. Ant-

292 dispersed seeds in these forests, including those of Asarum canadense, are primarily

293 dispersed in the spring (Thompson 1981). Temperatures in May in North Carolina and

294 June in Massachusetts at the study sites are far from the critical thermal maxima of ant

295 species in the system. For example, the critical thermal maximum for $A$. rudis is $38^{\circ} \mathrm{C}$ and 
$29640^{\circ} \mathrm{C}$ for populations at the northern and southern sites, respectively (Diamond et al.

297 2012b), as opposed to the mean environmental temperatures during the sampling period,

298 which were $20^{\circ} \mathrm{C}$ at the northern site and $22^{\circ} \mathrm{C}$ at the southern site. The thermal buffer

299 between $\mathrm{CT}_{\max }$ and the environmental temperature during the time of year when seeds are

300 dispersed may confer some degree of tolerance on this mutualism. Pelini (2011a) found

301 that rates of seed removal decreased in a passive experimental warming at the same two

302 sites, despite achieving warming of only $0.3^{\circ} \mathrm{C}$ above ambient. However, the seed

303 removal trials in Pelini et al.'s experiment were conducted mostly in August when

304 ambient environmental temperatures are hotter than those experienced in the present

305 study. We suggest that the proximity of ants to their upper thermal limits in August may

306 have driven the effects of warming observed in the Pelini et al. (2011a) study while seed

307 dispersal occurring in the spring when our study was conducted may be less likely to be

308 detrimentally impacted by warming. However, this protection assumes that the peak of $A$.

309 rudis activity and seed set coincide. Phenological shifts in plant reproduction caused by

310 ongoing warming (Price and Waser 1998, Dahlgren et al. 2007, Inouye 2008, Liu et al.

311 2011, Wolkovich et al. 2012) have the potential to result in seeds appearing before ants

312 become active (Warren et al. 2011). Warren et al. (2011) suggest that while both seed

313 release by plants and onset of foraging in ants seem to be driven by temperature,

314 variability in activation temperatures among ant species may result in situations in which

315 early seeding plant species may become decoupled from their foragers in some areas.

316 Despite the apparent tolerance of myrmecochory to experimental warming in this

317 study, there was a significant relationship between the ground-surface temperature at

318 which a species removed seeds and the critical thermal maximum of that species $\left(F_{1,4}=\right.$ 
$3197.35, p=0.05, R^{2}=0.65$, Fig. 3). That is, those species with high thermal tolerances were

320 most active under the warmest temperatures. The positive relationship between $\mathrm{CT}_{\max }$

321 and seed removal temperature suggests that while chronic experimental warming may not

322 affect rates of seed dispersal, temperature does relate to rates of seed removal. This

323 finding incorporates both temperature variability associated with the temperature

324 treatments as well as daily temperature variability and complements other studies that

325 have shown physiological tolerance to be an important predictor of ant activity (Diamond

326 et al. 2013).

327 One important caveat to our study (and to most studies of myrmecochory) is that

328 we do not know the ultimate fate of the seeds once the ants removed them. It is possible

329 that warming could still alter the dynamics of plant populations by altering rates of

330 germination and seedling survival post-germination (De Frenne et al. 2012), even in cases

331 in which seed dispersal remains unaffected as temperatures increases. Additionally, some

332 species, including C. lineolata, dispersed seeds very short distances (only a few

333 centimeters) while other species, such as C. castaneus, often carried seeds several meters

334 (Ness et al. 2004, personal observation) and species may vary in seed handling and where

335 they ultimately discard the seed (Hughes and Westoby 1992, Giladi 2006, Servigne and

336 Detrain 2010, Stuble et al. 2010). As such, even slight shifts in relative rates of dispersal

337 among these species may alter plant population dynamics if dispersal distances and seed

338 fate differ substantially among species (Bond and Slingsby 1984). Similarly, we have

339 grouped three species into the Aphaenogaster rudis complex. These species may differ in

340 their thermal niches and, as such, may respond differentially to warming. Past research

341 has, in fact, suggested that some of these species may be prone to phenological 
342 mismatches with their plant partners as a result of climatic warming (Warren et al. 2011,

343 Warren and Bradford 2013, Warren and Chick 2013). Finally, by observing seed caches

344 for an hour, we fail to collect data on the fate of seeds not removed in that time frame.

345 However, a considerable proportion of the seeds that will be removed by ants are, in fact, 346 removed soon after release from the parent plant (Turnbill and Culver 1983, Beaumont et

347 al. 2013) and seeds not dispersed by ants are at risk of predation by rodents (Heithaus

348 1981). Additionally, as in most studies of ant-seed interactions, we focus on seeds of only

349 a single plant species. Including more seeds from more species would be ideal, but would

350 have been beyond what was possible in this (or in most) studies.

351 It has become axiomatic that interactions among species are being affected by

352 ongoing climatic change. However, in this study, we found no reduction in overall rates

353 of seed removal as a result of experimental warming. Moreover, there were no

354 differences in species-specific seed removal rates at the southern site. We suggest that

355 myrmecochory may be resistant, at least in part, to climatic warming as a result of the

356 diversity of ants active in this mutualism as well as the seasonal timing of this mutualism

357 in the spring when most ant species are far from their upper thermal limits. Importantly,

358 however, if phenological mismatches arise, or if the fate of seeds after dispersal is altered,

359 the consequences of warming on plant populations and communities could emerge in 360 unexpected ways.

\section{Acknowledgements}

363 We thank M. Burt and I. Del Toro for help in the field. A. Ellison and N. Gotelli were 364 integral in developing and improving this project. We also thank K. Prior, R. Warren, and 
365 two anonymous reviewers for comments that aided in improving this manuscript. This 366 work was funded by the Department of Ecology and Evolutionary Biology at the 367 University of Tennessee, by and NSF DDIG and EPA STAR to K. Stuble, and by The US 368 Department of Energy Terrestrial Ecosystem Sciences Program (DE-FG02-08ER64510) 369 and US National Science Foundation (NSF 1136703) grants to N. Sanders and R. Dunn. 


\section{Work Cited}

Aizen, M. A., M. Sabatino, and J. M. Tylianakis. 2012. Specialization and rarity predict

Andrew, N. R., S. J. Hill, M. Binns, M. H. Bahar, E. V. Ridley, M.-P. Jung, C. Fyfe, M. Yates, and M. Khusro. 2013. Assessing insect responses to climate change: What are we testing for? Where should we be heading? PeerJ 1.

Bale, J. S., G. J. Masters, I. D. Hodkinson, C. Awmack, T. M. Bezemer, V. K. Brown, J. Butterfield, A. Buse, J. C. Coulson, J. Farrar, J. E. G. Good, R. Harrington, S. Hartley, T. H. Jones, R. L. Lindroth, M. Press, C., I. Symrnioudis, A. D. Watt, and J. B. Whittaker. 2002. Herbivory in global change research: direcrt effects of rising temperature on insect herbivores. Global Change Biology 8:1-16.

Barton, B. T., and O. J. Schmitz. 2009. Experimental warming transforms multiple predator effects in a grassland food web. Ecology Letters 12:1317-1325.

Beattie, A. J., and D. C. Culver. 1981. The guild of myrmecochores in the herbaceous flora of West Virginia forests. Ecology 62:107-115.

Beattie, A. J., and L. Hughes. 2002. Ant-plant interactions. Pages 211-235 in C. M. Herrera and O. Pellmyr, editors. Plant-animal interaction: an evolutionary approach. Blackwell, Oxford.

Beaumont, K. P., D. A. Mackay, and M. A. Whalen. 2013. Multiphase myrmecochory: the roles of different ant species and effects of fire. Oecologia 172:791-803.

Bond, W., and P. Slingsby. 1984. Collapse of an ant-plant mutalism: the Argentine ant (Iridomyrmex humilis) and myrmecochorous Proteaceae. Ecology 65:1031-1037.

Cain, M. L., and H. Damman. 1997. Clonal growth and ramet performance in the woodland herb, Asarum canadense. Journal of Ecology 85:883-897.

395 Callaway, R. M. 1995. Positive interactions among plants. Botanical Review 61:306-349.

396 Canner, J. E., R. R. Dunn, I. Giladi, and K. Gross. 2012. Redispersal of seeds by a keystone ant augments the spread of common wildflowers. Acta Oecologia 40:31-39.

401 Crist, T. O., and J. A. MacMahon. 1991. Foraging patterns of Pogonomyrmex occidentalis (Hymenoptera: Formicidae) in a shrub-steppe ecosystem: the roles of temperature, trunk trails, and seed resources. Environmental Entomology

$403 \quad 20: 265-275$. 
405

406

407

408

409

410

411

412

413

414

415

416

417

418

419

420

421

422

423

424

425

426

427

428

429

430

431

432

433

434

435

436

437

438

439

440

441

442

Dahlgren, J. P., H. von Zeipel, and J. Ehrlén. 2007. Variation in vegetative and flowering pheonolgy in a forest herb caused by environmental heterogeneity. American Journal of Botany 94:1570-1576.

De Frenne, P., B. J. Graae, J. Brunet, A. Shevtsova, A. De Schrijver, O. Chabrerie, S. A. O. Cousins, G. Decocq, M. Diekmann, M. Hermy, T. Heinken, A. Kolb, C. Nilsson, S. Stanton, and K. Verheyen. 2012. The response of forest plant regeneration to temperature variation along a latitudinal gradient. Annals of Botany 109:10371046.

Deutsch, C. A., J. J. Tewksbury, R. B. Huey, K. S. Sheldon, C. K. Ghalambor, D. C. Haak, and P. R. Martin. 2008. Impacts of climate warming on terrestrial ectotherms across latitude. Proceedings of the National Academy of Sciences of the USA - Biological Sciences 105:6668-6672.

Diamond, S. E., L. M. Nichols, N. McCoy, C. Hirsch, S. L. Pelini, N. J. Sanders, A. M. Ellison, N. J. Gotelli, and R. R. Dunn. 2012a. A physiological trait-based approach to predicting the responses of species to experimental climate warming. Ecology 93:2305-2312.

Diamond, S. E., C. A. Penick, S. L. Pelini, A. M. Ellison, N. J. Gotelli, N. J. Sanders, and R. R. Dunn. 2013. Using physiology to predict the responses of ants to climatic warming. Integrative and Comparative Biology 53:965-974.

Diamond, S. E., D. M. Sorger, J. Hulcr, S. L. Pelini, I. Del Toro, C. Hirsch, E. Oberg, and R. R. Dunn. 2012b. Who likes it hot? A global analysis of the climatic, ecological, and evolutionary determinants of warming tolerance in ants. Global Change Biology 18:448-456.

Dillon, M. E., G. Wang, and R. B. Huey. 2010. Global metabolic impacts of recent climate warming. Nature 467:704-706.

Fitzpatrick, M. C., N. J. Sanders, S. Ferrier, J. T. Longino, M. D. Weiser, and R. R. Dunn. 2011. Forecasting the future of biodiversity: a test of single- and multi-species models for ants in North America. Ecography 34:836-847.

Gibb, H., and C. L. Parr. 2010. How does habitat complexity affect foraging success? A test using functional measures on three continents. Oecologia 164:1061-1073.

Giladi, I. 2006. Choosing benefits or partners: a review of the evidence for the evolution of myrmecochory. Oikos 112:481-492.

Gove, A. D., J. D. Majer, and R. R. Dunn. 2007. A keystone ant species promotes seed dispersal in a "diffuse" mutualism. Oecologia 153:687-697.

Harley, C. D. G. 2011. Climate change, keystone predation, and biodiversity loss. Nature 334:1124-1127.

Heithaus, E. R. 1981. Seed predation by rodents on three ant-dispersed plants. Ecology 62:136-145. 
Hodgson, E. S. 1955. An ecological study of the behavior of the leaf-cutting ant Atta cephalotes. Ecology 36:293-304.

445

446

447

448

449

450

451

452

453

454

455

456

457

458

459

460

461

462

463

464

465

466

467

468

469

470

471

472

473

474

475

476

477

478

Hoover, S. E. R., J. J. Ladley, A. A. Shchepetkina, M. Tisch, S. P. Gieseg, and J. M. Tylianakis. 2012. Warming, CO2, and nitrogen deposition interactively affect a plant-pollinator mutualism. Ecology Letters 15:227-234.

Huey, R. B., M. R. Kearney, A. Krockenberger, J. A. M. Holtum, M. Jess, and S. E. Williams. 2012. Predicting organismal vulnerability to climate warming: roles of behaviour, physiology and adaptation. Philosophical Transactions of the Royal Society B 367:1665-1679.

Hughes, L., and M. Westoby. 1992. Fate of seeds adapted for dispersal by ants in Australian sclerophyll vegetation. Ecology 73:1285-1299.

Inouye, D. W. 2008. Effects of climate change on phenology, frost damage, and floral abundance of montane wildflowers. Ecology 89:353-362.

King, J. R., R. J. Warren, and M. A. Bradford. 2013. Social insects dominate eastern US temperate hardwood forest macroinvertebrate communities in warmer regions. PLOS One 8:e75843.

Klein, J. A., J. Harte, and X.-Q. Zhao. 2004. Experimental warming causes large and rapid species loss, dampened by simulated grazing on the Tibetan Plateau. Ecology Letters 7:1170-1179.

Lengyel, S., A. D. Gove, A. M. Latimer, J. D. Majer, and R. R. Dunn. 2010. Convergent evolution of seed dispersal by ants, and phylogeny and biogeography in flowering plants: A global survey. Perspectives in Plant Ecology, Evolution and Systematics 12:43-55.

Liu, Y., P. B. Reich, G. Li, and S. Sun. 2011. Shifting phenology and abundance under experimental warming alters trophic relationships and plant reproductive capacity. Ecology 92:1201-1207.

Memmott, J., P. G. Craze, N. M. Waser, and M. V. Price. 2007. Global warming and the disruption of plant-pollinator interactions. Ecology Letters 10:710-717.

Michaels, H. J., B. Benner, A. P. Hartgerink, T. D. Lee, and S. Rice. 1988. Seed size variation: magnitude, distribution, and ecological correlates. Evolutionary Ecology 2:157-166.

Morales, M. A., and E. R. Heithaus. 1998. Food from seed-dispersal mutualism shifts sex ratios in colonies of the ant Aphaenogaser rudis. Ecology 79:734-739.

Narendra, A., S. Reid, and J. M. Hemmi. 2010. The twilight zone: ambient light levels trigger activity in primitive ants. Proceedings of the Royal Society B: Biological Sciences 277:1531-1538. 
479

480

481

482

483

484

485

486

487

488

489

490

491

492

493

494

495

496

497

498

499

500

501

502

503

504

505

506

507

508

509

510

511

512

513

514

515

Ness, J. H., J. L. Bronstein, A. N. Andersen, and J. N. Holland. 2004. Ant body size predicts dispersal distance of ant-adapted seeds: implications of small-ant invasions. Ecology 85:1244-1250.

Ness, J. H., D. F. Morin, and I. Giladi. 2009. Uncommon specialization in a mutualism between a temperate herbaceous plant guild and an ant: are Aphaenogaster ants keystone mutualists? Oikos 118:1793-1804.

Norby, R. J., and Y. Luo. 2004. Evaluating ecosystem responses to rising atmospheric $\mathrm{CO} 2$ and global warming in a multi-factor world. New Phytologist 162:281-283.

Parrent, J. L., W. F. Morris, and R. Vilgalys. 2006. CO2-enrichment and nutrient availability alter ectomycorrhizal fungal communities. Ecology 87:2278-2287.

Pelini, S. L., M. Boudreau, N. McCoy, A. M. Ellison, N. J. Gotelli, N. J. Sanders, and R. R. Dunn. 2011a. Effects of short-term warming on low and high latitude forest ant communities. Ecosphere 2:1-12.

Pelini, S. L., F. P. Bowles, A. M. Ellison, N. J. Gotelli, N. J. Sanders, and R. R. Dunn. 2011b. Heating up the forest: open-top chamber warming manipulation of arthropod communities at Harvard and Duke Forests. Methods in Ecology and Evolution 2:534-540.

Peterson, G., C. R. Allen, and C. S. Holling. 1998. Ecological resilience, biodiversity, and scale. Ecosystems 1:6-18.

Price, M. V., and N. M. Waser. 1998. Effects of experimental warming on plant reproductive phenology in a subapline meadow. Ecology 79:1261-1271.

Rico-Gray, V., and P. S. Oliveira. 2007. The Ecology and Evolution of Ant-Plant Interactions. The University of Chicago Press, Chicago, IL.

Rothley, K. D., and G. Dutton. 2006. Behavioral responses to environmental change alter direct and indirect trait-mediated interactions. Canadian Journal of Zoology 84:1053-1058.

Sanders, N. J., and D. M. Gordon. 2000. The effects of interspecific interactions on resource use and bahavior in a desert ant. Oecologia 125:436-443.

Sanders, N. J., and D. M. Gordon. 2003. Resource-dependent interactions and the organization of desert ant communities. Ecology 84:1024-1031.

Servigne, P., and C. Detrain. 2010. Opening myrmecochory's black box: what happens inside the ant nest? . Ecological Research 25:663-672.

Sheldon, K. S., S. Yang, and J. J. Tewksbury. 2011. Climate change and community disassembly: impacts of warming on tropical and temperate montane community structure. Ecology Letters 14:1191-1200.

Stachowicz, J. J. 2001. Mutualisms, facilitation, and the structure of ecological communities. BioScience 51:235-246. 
516

Stuble, K. L., L. K. Kirkman, and C. R. Carroll. 2010. Are red imported fire ants facilitators of native seed dispersal? . Biological Invasions 12:1661-1669.

Stuble, K. L., S. L. Pelini, S. E. Diamond, D. A. Fowler, R. R. Dunn, and N. J. Sanders. 2013a. Foraging by forest ants under experimental warming: a test at two sites. Ecology and Evolution 3:482-491.

Stuble, K. L., M. A. Rodriguez-Cabal, G. L. McCormick, I. Jurić, R. R. Dunn, and N. J. Sanders. 2013b. Tradeoffs, competition, and coexistence in eastern deciduous forest ant communities. Oecologia 171:981-992.

Suttle, K. B., M. A. Thomsen, and M. E. Power. 2007. Species interactions reverse grassland responses to changing climate. Science 315:640-642.

Thompson, J. N. 1981. Elaiosomes and fleshy fruits: phenology and selection pressures for ant-dispersed seeds. American Naturalist 117:104-108.

Turnbill, C. L., and D. C. Culver. 1983. The timing of seed dispersal in Viola nuttallii: attraction of dispersers and avoidance of predators. Oecologia 59:360-365.

Turner, K. M., and M. E. Frederickson. 2013. Signals can trump rewards in attracting seed-dispersing ants. PLOSOne 8:e71871.

Tylianakis, J. M., R. K. Didham, J. Bascompte, and D. A. Wardle. 2008. Global change and species interactions in terrestrial ecosystems. Ecology Letters 11.

Urban, M. C., J. J. Tewksbury, and K. S. Sheldon. 2012. On a collision course: competition and dispersal differences create no-analogue communities and cause extinctions during climate change. Proceedings of the Royal Society B: Biological Sciences 279:2072-2080.

van der Putten, W. H., M. Macel, and M. E. Visser. 2010. Predicting species distribution and abundance responses to climate change: why it is essential to include biotic interactions across trophic levels. Philosophical Transactions of the Royal Society B 365:2025-2034.

Villalpando, S. N., R. S. Williams, and R. J. Norby. 2009. Elevated air temperature alters an old-field insect community in a multifactor climate change experiment. Global Change Biology 15:930-942.

Walther, G.-R. 2010. Community and ecosystem responses to recent climate change. Philosophical Transactions of the Royal Society B 365:2019-2024.

Warren, R. J., V. Bahn, and M. A. Bradford. 2011. Temperature cues phenological synchrony in ant-mediated seed dispersal. Global Change Biology 17:2444-2454.

Warren, R. J., and M. A. Bradford. 2013. Mutualism fails when climate response differs between interacting species. Global Change Biology 20:466-474. 
551

552

553

554

555

556

557

558

559

560

561

562

563

564

565

566
Warren, R. J., and L. Chick. 2013. Upward ant distribution shift corresponds with minimum, not maximum, temperature tolerance. Global Change Biology 19:20822088.

Whitford, W. G., and G. Ettershank. 1975. Factors affecting foraging activity in Chihuahuan Desert Harvester ants. Environmental Entomology 4:689-696.

Wolkovich, E. M., B. I. Cook, J. M. Allen, T. M. Crimmins, J. L. Betancourt, S. E. Travers, S. Pau, J. Regetz, T. J. Davies, N. J. B. Kraft, T. R. Ault, K. Bolmgren, S. J. Mazer, G. J. McCabe, B. J. McGill, C. Parmesan, N. Salamin, M. D. Schwartz, and E. E. Cleland. 2012. Warming experiments underpredict plant phenological responses to climate change. Nature 485:494-497.

Zelikova, T. J., R. R. Dunn, and N. J. Sanders. 2008. Variation in seed dispersal along an elevational gradient in Great Smokey Mountains National Park. Acta Oecologia 34:155-162. 


\section{Table 1 (on next page)}

Table 1. Test statistics are from linear regressions examining the influence of temperature treatment on the number of seeds removed by each ant species (d.f. $=11$ for all species). 


Species
\begin{tabular}{|l|r|r|}
\hline Aphaenogaster lamellidens & \multicolumn{2}{l}{$\boldsymbol{p}$} \\
\hline Aphaenogaster rudis & 2.58 & 0.58 \\
\hline Camponotus castaneus & 2.45 & 0.15 \\
\hline Camponotus pennsylvanicus & 0.10 & 0.75 \\
\hline Crematogaster lineolata & 0.24 & 0.64 \\
\hline Formica pallidefulva & 0.14 & 0.07 \\
\hline Formica subsericea & 0.34 & 0.58 \\
\hline
\end{tabular}




\section{Table 2 (on next page)}

Table 2. Percentage of seeds removed by each species overall, during the day, and the night. 


\begin{tabular}{|l|r|r|r|}
\multicolumn{1}{l}{ Species } & \multicolumn{1}{c}{$\begin{array}{l}\text { Overall } \\
\text { percent }\end{array}$} & \multicolumn{1}{l}{$\begin{array}{l}\text { Day } \\
\text { percent }\end{array}$} & \multicolumn{1}{l}{$\begin{array}{l}\text { Night } \\
\text { percent }\end{array}$} \\
\hline Aphaenogaster lamellidens & 8.5 & 17.2 & 0.0 \\
\hline Aphaenogaster rudis & 45.5 & 48.3 & 42.7 \\
\hline Camponotus castaneus & 26.7 & 0.0 & 52.8 \\
\hline Camponotus pennsylvanicus & 2.8 & 2.3 & 3.4 \\
\hline Crematogaster lineolata & 6.8 & 12.6 & 1.1 \\
\hline Formica pallidefulva & 2.3 & 4.6 & 0.0 \\
\hline Formica subsericea & 7.4 & 14.9 & 0.0 \\
\hline
\end{tabular}




\section{Figure 1}

Figure 1. Warming chamber at Duke Forest.

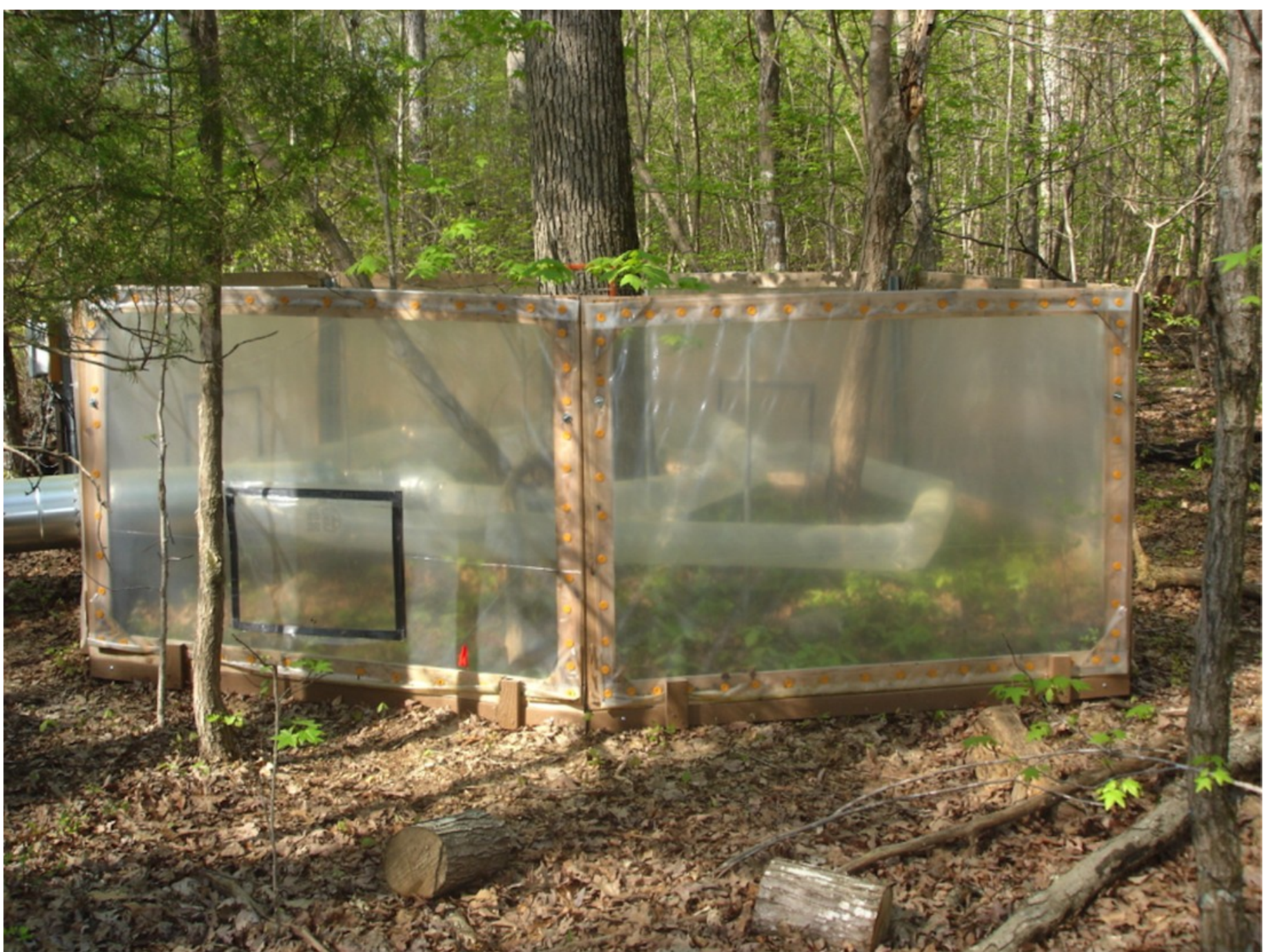




\section{Figure 2}

Figure 2. Number of seeds removed ( \pm standard error) in the course of an hour as a function of temperature treatment. Black dots represent Duke Forest and gray dots represent Harvard Forest.

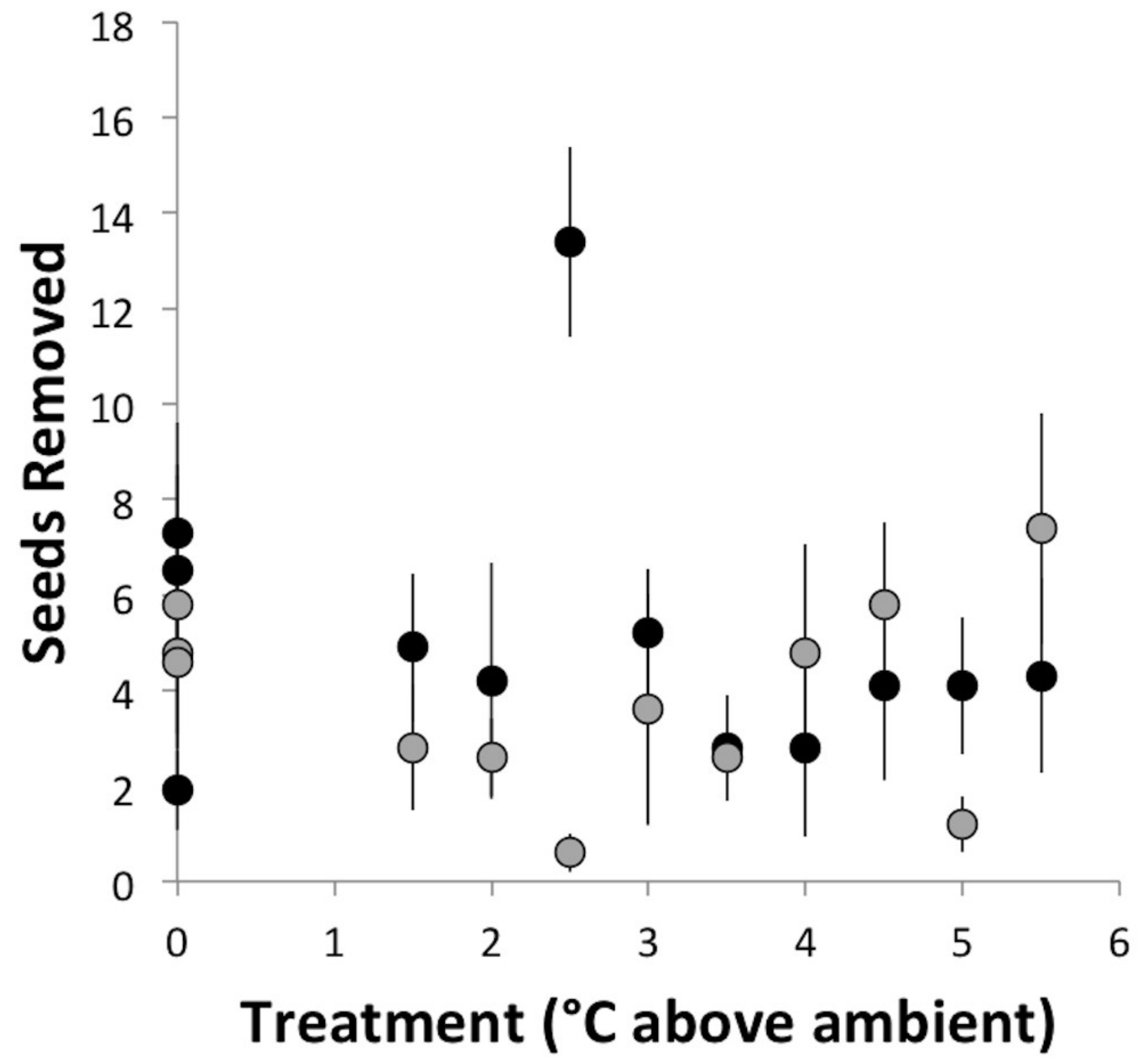




\section{Figure 3}

Figure 3. Temperature ( \pm standard error) at which seeds were removed as a function of a species' critical thermal maximum (CTmax).

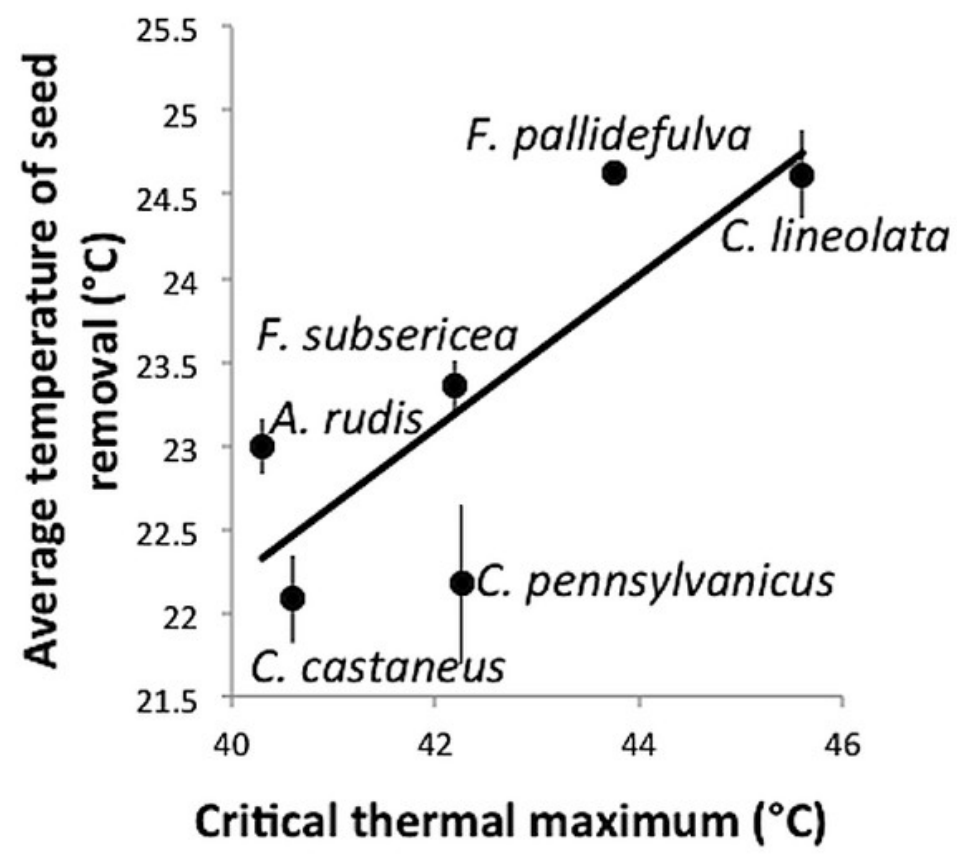

